\title{
Cartes de Palmira Jaquetti a Rafael Patxot i Jubert (1938-1939)
}

Josep Massot i Muntaner Institut d'Estudis Catalans massotmuntaner@gmail.com

\section{RESUM}

Aquest treball es basa en nou cartes, inèdites i desconegudes fins ara, procedents d'un arxiu privat, adreçades per la professora, poeta i folklorista Palmira Jaquetti (Barcelona, I895-els Monjos, I963) al gran mecenes català Rafael Patxot i Jubert (Sant Feliu de Guíxols, I872-Ginebra, I964). Escrites el I938 i el I939, durant els anys finals de la guerra civil espanyola, ens permeten de conèixer tot un seguit de detalls nous sobre la malaltia crònica que va patir Jaquetti des del I934 i sobre les seves vicissituds biogràfiques. Abandonada pel seu marit el I937, va poder sortir de l'hospital el I938 i de seguida es va reincorporar a l'Institut Pi i Margall de Barcelona, on ensenyava francès. Gran col-laboradora de l'Obra del Cançoner Popular de Catalunya, patrocinada per Patxot, va aconseguir un permís per traslladar-se durant una temporada d'estiu a Prats de Molló, a la Catalunya del Nord. Va poder dur-ho a terme, però el seu estat de salut l'obligà a dedicar-se només al descans. En acabar la guerra, fou sotmesa a un expedient de depuració, resolt el I94I d'una manera relativament benigna. Malgrat la repressió franquista, va continuar encara les seves recerques folklòriques —que l'havien duta a recollir deu mil cançons populars catalanes-, tant a la vall d'Aran com en sis asils de Barcelona.

Paraules Clau

Palmira Jaquetti; Rafael Patxot i Jubert; Enric D'Aoust; Obra del Cançoner Popular de Catalunya; guerra civil espanyola 


\begin{abstract}
This study is based on nine previously unpublished and unknown letters from a private archive, written by the teacher, poet and folklorist Palmira Jaquetti (Barcelona, I895 - els Monjos, I963) to the great Catalan patron Rafael Patxot i Jubert ( Sant Feliu de Guixols, I872 - Geneva, I964). Written in I938 and I939, during the final years of the Spanish Civil War, they reveal a whole series of new details about the chronic illness that Jaquetti suffered from I934 and about the twists and turns of her life. Abandoned by her husband in I937, she was able to leave the hospital in 1938 and soon returned to the Institut Pi i Margall in Barcelona where she taught French. A great collaborator in the Popular Song Book of Catalonia, patronized by Patxot, she obtained a permit to spend a summer in Prats de Molló in Northern Catalonia. She was able to go, but her state of health forced her to devote herself only to rest. At the end of the Civil War, she was affected by a purge which was ultimately resolved in I94I in a relatively benign manner. Despite Franco's repression, she continued her folk research - which led her to collect ten thousand Catalan folk songs - both in the Aran Valley and in six asylums in Barcelona.
\end{abstract}

\title{
KEYWORDS
}

Palmira Jaquetti; Rafael Patxot i Jubert; Enric D'Aoust; Popular Song Book of Catalonia; Spanish Civil War

REBUT: 27/O2/2O2O | ACCEPTAT: I4/O4/2O2O 
$\mathrm{E}$ 1 nom de Palmira Jaquetti és ben viu en el món dels poetes i dels folkloristes, i igualment, encara que potser no tant, en el dels pedagogs i el dels músics. No sempre, però, ens n'ha arribat un record excessivament precís, a vegades per culpa de la mateixa Jaquetti, que uns anys abans de morir va redactar un esbós d'autobiografia, publicada per la seva biògrafa Roser Matheu (I972: I69-I92), que, al costat de detalls d'una absoluta exactitud, afavoreix una mitologia que no sempre li resulta favorable i ens la presenta com una persona una mica original, incapaç de redactar un text coherent i de lectura àgil i entenedora. A vegades se'ns parla d'ella com si fos la primera dona que es va dedicar a recollir cançons populars catalanes, oblidant que s'inscriu dins una llarga tradició que ja comença al segle xix (Oriol-Samper 20I7), o l'única dona que va col-laborar en la magna Obra del Cançoner Popular de Catalunya, tot i que al seu costat trobem també les seves col-laboradores Maria Carbó i Mercè Porta i Pino, i la mallorquina Dolors Porta. Més sorprenent és que les memòries de missions de recerca que va escriure - algun cop amb l'ajuda del seu marit Enric D'Aoust- per acompanyar les cançons que recollia per a l'Obra del Cançoner siguin magnificades per alguns i convertides en una obra mestra, mentre que d'altres pensen que resulten massa líriques i poc adequades per al seu objectiu, com sí que ho són les de Joan Tomàs, de Joan Amades o de Baltasar Samper. En general, es repeteix la dada, procedent de la mateixa Jaquetti, que la seva aportació a l'Obra del Cançoner arribava a la xifra astronòmica de deu mil documents, precisament la mateixa quantitat que reivindicaven, per separat, Joan Tomàs i Joan Amades, amb una certa exageració (Tomàs 2008: II9, I77 i I79-I80). Altres, en canvi, redueixen aquesta xifra a mil cinc-cents documents, molt inferior a la real, que, com veurem, realment sobrepassa els deu mil. I no manca qui situï a la Biblioteca de Catalunya aquest material, en realitat conservat a l'arxiu de l'Obra del Cançoner Popular de Catalunya, a l'Abadia de Montserrat.

Podríem trobar les mateixes contradiccions a l'hora de valorar la personalitat de Palmira Jaquetti, tant des del punt de vista humà com des de la seva àmplia activitat pedagògica. Mentre alguns en parlen amb entusiasme i asseguren que els seus alumnes - les seves alumnes sobretot, d'ençà que va treballar a l'Institut Montserrat- en tenien un record excel-lent, altres persones que la van conèixer de prop es queixen de les seves excentricitats, de la seva manca de sentit de la realitat i del seu egocentrisme, que sovint la convertia en pidolaire.

Sigui com sigui, Palmira Jaquetti és una figura rellevant en els camps en què es va moure: la poesia, l'ensenyament - acompanyat de la composició de la lletra i de la música de cançons senzilles per a infants- i sobretot la infatigable recerca de camp per a l'Obra del Cançoner i més endavant per al Consejo Superior de Investigaciones Científicas. En homenatge a la seva memòria, resseguiré ràpidament la seva feina com a folklorista i m'entretindré sobretot en un dels aspectes més desconeguts de la seva vida: la tragèdia que van representar per a ella els anys de la guerra civil i els del primer franquisme, sobre els quals he pogut consultar, en un arxiu particular, un tou de cartes en francès i en català d'una importància extraordinària.

No sabem d'on prové l'interès constant de Palmira Jaquetti per la cançó popular. Sí que ens consta, per ella mateixa, que havia cursat estudis de música a l'Escola Municipal de Barcelona i al Conservatori del Liceu i que no ho deixà mai, malgrat tota la resta de matèries a què hagué de dedicar moltes hores per acu- 
mular els títols de mestra, de batxiller i de llicenciada en Filosofia i Lletres, a més d'aprofundir pel seu compte en diversos idiomes — sobretot el francès, el coneixement del qual li va valer, ja el I932, una càtedra d'institut- i en la història de l'art, de la qual va donar classes particulars.

No ens consta que tingués cap contacte amb Rossend Serra i Pagès, que va engrescar tota una colla de noies a dedicar-se poc o molt a les branques més diverses del folklore. Algú assegura, però, que entre els seus professors de música hi havia Francesc Pujol, sotsdirector de l'Orfeó Català i director de l'Obra del Cançoner Popular de Catalunya, promoguda el I92I pel gran mecenes català Rafael Patxot i Jubert (cf. Massot 20I4), i és molt possible que tingués alguna relació — directa o indirecta- amb Felip Pedrell, que va exercir una gran influència a través de les seves publicacions de música popular. En qualsevol cas, el primer contacte de Palmira Jaquetti amb l'Obra del Cançoner va ésser el I923, amb motiu del concurs convocat el 1922 i resolt l'any següent. Palmira, que aleshores tenia 27 anys, hi participà amb el recull Cançons populars catalanes, que duia el lema Les velles cançons, dolces $i$ belles i que va rebre un accèssit de 75 pessetes.

El I6 de juny de i923, Jaquetti va visitar per primer cop l'oficina de l'Obra del Cançoner i s'hi va declarar autora del recull i resident a Barcelona (Massot [ed.] I995: 53). Es tractava d'una aportació molt breu: un conjunt de 55 cançons dividides en diversos blocs temàtics: cants patriòtics, oracions, de bressol i diverses, cançons de romanç, i cançons divertides i de disbarats i vàries. ${ }^{I}$ Amb l'estil poc acurat que tindrà sempre, Palmira omple de petits papers plens de notes els diversos blocs i comença excusant-se'n:

Aquest recull de cançons no fou fet amb mires a un concurs, puig no n'erem assabentats.- Per això la documentació no és massa complerta. Però: he recollit a Vilaplana, ${ }^{2}$ en febrer i març i juliol de I92I. A Solsona en juliol I92I totes les cançons i tenint-hi família em seria facilíssim documentar-me si fos necessari.

Tot contradient-se, afirma en una altra anotació titulada Solsona:

Totes les recollides a Solsona ho són en [a sota: «juliol I922»] una casa de camp a una hora de Solsona, pujant cap a muntanya, que es dos cases més amunt de la que en diuen «la Canal».- Es un vell d'uns 70 anys, fort, prim i petitó, que guarda els bous. Tot guardant canta. Es l'amo de la casa. I ell guarda la butxaca, (el fill casat) i és molt amic del beure, de la broma i de l'alegria. No em recorda el seu nom.

I en una altra referent a una «dona pagesa» de Vilaplana posa igualment la data «Juliol I922». Altres apunts del mateix recull ens permeten de saber que ales-

I Arxiu de l'Obra del Cançoner Popular de Catalunya (Abadia de Montserrat), C-I88.

2 Es tracta del poblet Vilaplana del Camp, atès que a la seva autobiografia Jaquetti escriu, altra vegada contradient-se en alguns punts: «Havia acabat [quan li foren encomanades les primeres missions de l'Obra del Cançoner Popular de Catalunya] la carrera de mestra, per oposicions, i guanyat una escola a Vilafranca. Allà recollia, durant la meva curta estada de poc més d'un mes, totes les cançons de la plana de Reus que, ajuntades a les de la meva mare, que cantava molt bé, i presentades a concurs de l'Orfeó Català, guanyaren el premi que em féu coneguda en aquella entitat.» Una mica més endavant, assegura que «havia ja escorcollat, també pel meu compte, tota la comarca de Solsona, on vivien i viuen encara les meves cosines» (Matheu: 1972: 180). 
hores Jaquetti ja coneixia i utilitzava el Romancerillo de Milà i Fontanals, un dels instruments bàsics per als «missioners» de l'Obra del Cançoner.

No és estrany, doncs, que Francesc Pujol — tant si havia estat professor de la Palmira com si la va conèixer el I923- pensés en ella per encarregar-li de formar part de l'equip que d'una manera sistemàtica recorria les diverses contrades dels països de llengua catalana, sobretot aprofitant els estius, durant els quals els qui exercien l'ensenyament tenien unes llargues vacances. ${ }^{3}$ En efecte, el Dietari de l'Obra del Cançoner ens permet de saber que el 6 de juliol de I925, el mestre Pujol, en una visita a l'oficina de l'Obra, va encomanar «que siguin enllestides per demà tres còpies d'una mostra de contracte de l'Obra amb els missioners de recerca, perquè diu que demà vindran per firmar-les Na Palmira Jaquetti i Na Maria Assumpta Pasqual, de 1' "Institut de Cultura", ${ }^{4}$ que aniran a fer una missió de recerca a la Seu d'Urgell i comarca». (Massot [ed.] I995: IO4) L'endemà, però, Pujol tornà a l'oficina «advertint que a la missió de la Seu hi anirà, en comptes de Na Maria Assumpta Pasqual, Na Maria Carbó i Soler, també de l' "Institut" [de Cultura de la Dona], i que aquesta i sa companya no vindran avui sinó demà» (Massot [ed.] I995: Io4) El 8 de juliol de I925, doncs, Jaquetti i Carbó signaren les anomenades Ordenacions de missió, davant el mestre Pujol i el tresorer de l'Orfeó Català, Tomàs Millet, i van rebre «cabals i instruccions per a la tasca que van a emprendre» (Massot [ed.] I995: IO4). Sense perdre ni un minut, i amb la rapidesa de sempre, l'endemà dia 9 les dues missioneres van agafar el primer tren per anar cap a la Seu d'Urgell (Massot [ed.] I995: I04), i el 3 de setembre ja tornaven a ésser a Barcelona, després de passar per la Vall d'Aran i de fer una escapada a França, tot i que des de l'oficina els haguessin demanat que no s'hi internessin, davant el perill d'ésser detingudes en tornar a passar la frontera (Massot [ed.] I995: IO7-IIO).

Els resultats obtinguts en aquesta primera missió no podien ésser més espectaculars: un conjunt de quatre grans carpetes, amb un total de 637 documents, més la memòria corresponent - plena d'informacions i d'observacions, en les quals sobresortia també l'amor per la natura que Palmira Jaquetti demostrà sempre- i un bon nombre de fotografies. Aquesta tònica, fruit d'una enorme capacitat de treball i d'un amor profund per les cançons populars, es va mantenir al llarg dels anys. L'estiu de 1926, Palmira Jaquetti tornà a treballar amb Maria Carbó, aquest cop al Pallars i a la Conca de Tremp, i en dos mesos van recollir I.4I2 documents. Els nou primers dies de gener de I927, totes dues van fer una petita missió a Sant Feliu de Guíxols, no exempta de dificultats; així i tot, en dugueren I6o documents. L'estiu del mateix any I927, Palmira canvià de parella: des d'aleshores i fins al I930, l'acompanyà l'escriptor i pintor belga Enric D'Aoust, onze anys més jove que ella, amb qui es va casar a Montserrat el 27 de juny i l'endemà mateix partiren cap al Pallars i la Ribagorça, d'on van tornar amb r.6oo documents. Incansables, tant l'un com l'altre, del 25 al 28 de desembre del mateix any, Jaquetti i D'Aoust van fer una petita missió a Torroella de Montgrí i a l'Estartit, amb un resultat molt migrat (només 58 documents). L'estiu de I928, tornaren al Pallars, altre cop amb

3 Per a l'Obra del Cançoner Popular de Catalunya, vegeu Massot (en premsa), en el qual lògicament són ressenyades totes les missions que va dur a terme Palmira Jaquetti.

4 És a dir, l'Institut de Cultura de la Dona, fundat a Barcelona per Francesca Bonnemaison, que tingué sempre el suport de Rafael Patxot. La relació que hi tenien Jaquetti i Carbó explica que el 3 de gener de 1926 hi llegissin fragments de la memòria de la missió i hi cantessin alguna de les cançons recollides (Massot [ed.] I995: I22). 
una collita abundosa (I.40o documents), i del 23 de desembre de 1928 fins al 2 de gener de I929 van dur a terme també una altra petita missió a Torroella, Verges, Pals i l'Escala, amb un èxit sorprenent (I74 documents). L'estiu de I929, el matrimoni Jaquetti-D'Aoust va tornar a la Ribagorça, altre cop amb un resultat excel-lent (I.374 documents), i del 24 al 30 de desembre repetiren la visita a l'Escala, on aconseguiren Io7 documents. El I930 van fer una única missió a l'estiu, del 29 d'agost al 2I de setembre, altre cop a Verges i als pobles de la rodalia, amb un resultat de 570 documents. En una data indeterminada de I930, Jaquetti i D'Aoust van fer donació a l'arxiu de l'Obra del Cançoner Popular de Catalunya d'un «aplec de 25 cançons, recollides de Na Josepa Bosch, filla de Fornells de la Selva i resident a Barcelona» (Massot [ed.] I995: I99). ${ }^{5}$

En aquells moments, les relacions entre Palmira Jaquetti i el seu marit començaren a trontollar i segurament per això l'estiu de I93I Jaquetti va tornar a la Ribagorça i al Pallars amb Maria Carbó. Un cop més, les cançons van rajar i hi recolliren I.III documents. Palmira, però, acabava la seva extensa memòria amb unes reflexions que em fan pensar en la preocupació que ja devia tenir respecte al seu matrimoni: «La petitesa humana», deia, «ensems que la preciosa adaptació al moment, se'm fan foteses sovint, però sobretot quan em deixo dur, com ara, per la rapidesa que brinda paisatge i emocions fugisseres, que són, tot i el control de la pròpia incontinència, l'encís de la vida, el meu conte de fades» (Massot [ed.] 2004a: 177).

El I932, Palmira Jaquetti no va treballar per a l'Obra del Cançoner, molt probablement perquè li ho impediren les gestions que devia haver de fer per aconseguir una càtedra de francès a l'Institut de Calataiud, ${ }^{6}$ aviat seguit d'un trasllat teòric a Reus i d'una comissió de serveis a l'Institut Escola, en el seu cas la seva filial Institut Pi i Margall, creat el I933 a la cruilla dels carrers de Rosselló i Balmes de Barcelona, en un local que havia pertangut als jesuïtes abans de ser dissolt per les Corts republicanes, que els fou retornat després de la guerra civil (Domènech I998: 34I-346).

L'estiu de I933, però, Palmira va reprendre la tasca, aquest cop acompanyada d'una deixebla seva, Mercè Porta i Pino, bibliotecària de l'Institut per la Cultura de la Dona. Totes dues van anar el 26 d'agost d'aquell any a les oficines de l'Obra del Cançoner, el Dietari de la qual ens permet de saber que estaven «a punt de començar una missió de recerca i recollida per terres de Cerdanya, demanant-nos que els fem una lletra d'autorització per mostrar-la quan i a qui convingui durant llur expedició. Els la redactem i fem a mans» (Massot [ed.] I995: 217). Les missioneres van sortir de Barcelona, cap a Setcases i Tregurà, el dia 27 d'agost i acabaren la feina el 23 de setembre (Massot [ed.] I995: 216 i 217). Aquest cop «només» havien pogut recollir 558 documents. L'estiu de l'any següent, Jaquetti i Porta van dur a terme el que seria la seva darrera missió «oficial» per a l'Obra del Cançoner,

5 Aquest aplec es conserva encara a l'esmentat arxiu, C-2II.

6 El 28 de desembre de I93I, el Dietari de l'Obra del Cançoner Popular de Catalunya anota: «Visita l'oficina del "Cançoner" Na Palmira Jaquetti de D'Aoust, que ha realitzat vàries missions de recerca i recollida de cançons i músiques populars a compte i per encàrrec de l'Obra. Ara és catedràtica de l'Institut de segona ensenyança de la ciutat aragonesa Calataiud i en aquestes vacances nadalenques, passades per ella a Barcelona, al costat de la seva família, ha tingut envers l'Obra l'atenció, que molt és estimada, de visitar-ne les oficines» (Massot [ed.] I995: 2II). 
a Molló, Prats de Molló i Pardines, en la qual aconseguiren 543 documents. Tot plegat, doncs, ens trobem amb l'enorme xifra de gairebé deu mil peces, a les quals cal afegir encara les que Palmira va aconseguir a les petites missions «voluntàries» de I936, I937 i I940, a les quals em referiré tot seguit.

El I8 de juliol de I934 es va acabar, doncs, la col·laboració de Palmira Jaquetti a l'Obra del Cançoner, que dos anys més tard, el is de juliol de I936, hagué de tancar les portes, arrossegada per la situació que es va viure a Catalunya i a la resta de l'Estat espanyol després de la revolta civicomilitar que va esclatar el I7 d'aquell mateix mes i que donaria lloc a una guerra civil fratricida, que duraria, segons els vencedors, fins a l'I d'abril de i939. Durant aquest temps, Palmira Jaquetti va viure una tragèdia personal, que es va veure agreujada per la guerra i per les seves conseqüències. Fins ara en sabíem molt poca cosa i havíem d'avançar entre hipòtesis no sempre segures. No fa gaire, però, com ja he insinuat, vaig tenir la sort de localitzar un extens conjunt de cartes adreçades, entre el I938 i el I939, per Palmira Jaquetti al mecenes de l'Obra del Cançoner Popular de Catalunya, Rafael Patxot i Jubert, amb el qual havia tingut un tracte directe mentre duia a terme les successives missions, ben especialment la de Sant Feliu de Guíxols, on Patxot va néixer i on se sentia molt arrelat, encara que fes anys que s'havia establert a Barcelona.7 Les publico senceres en aquest treball, però m'ha semblat convenient d'afegir-hi algunes pinzellades prèvies per situar-les dins el seu context.

El 6 d'octubre de I934, Palmira Jaquetti va caure malalta, ${ }^{8}$ d'una malaltia que no sabem exactament en què consistia ni d'on provenia. 9 Sí que sabem que era llarga i molt dolorosa ${ }^{\mathrm{IO}}$ i que l'obligà a sofrir moltes operacions dels genolls i de les cames i la deixà en part invàlida i necessitada de caminar amb un bastó, no amb una crossa, segons especifica ella mateixa (vegeu doc. I i una mica a tot arreu). ${ }^{\text {II }}$ Inicialment, el seu marit la va portar a l'Hospital de Sant Pau, d'on va sortir el juny de I937. No la van donar, però, d'alta, sinó que la traslladaren a un balneari de Tona, on va passar almenys del i8 fins al 30 de juliol a fi d'enfortir-se i poder tornar a una vida relativament normal (doc. I). Malgrat la seva situació i malgrat el dolor que sentia perquè el seu marit havia decidit abandonar-la, ${ }^{12}$ no va oblidar la seva dèria per les cançons populars, que va recollir, d'una manera més aviat

7 He pogut veure una llarga carta de Palmira Jaquetti a Rafael Patxot en la qual li parla de molts detalls d'aquesta missió, que sens dubte ell li havia encarregat directament, al mateix temps que li feia suggeriments per trobar persones que hi ajudessin. Aquesta carta ens permet d'assegurar que aleshores Palmira tenia una bona relació amb la família Patxot i sentia una profunda veneració pel seu cap de casa.

8 Segons l'autobiografia publicada a Matheu (I972: 182).

9 Roser Matheu (I972: I75) dona a entendre que estava relacionada d'alguna manera amb el marit de Palmira Jaquetti.

Io A banda de les referències que hi fa Palmira, podem assenyalar que el Dietari de l'Obra del Cançoner assenyala el 3 de març de I936: «Na Palmira Jaquetti, que havia realitzat vàries missions de recerca i recollida de cançons en anys passats i que ara ja fa temps que es troba hospitalitzada per una dolença dissortadament molt llarga, fa arribar a mans dels que treballem a l'oficina del Cançoner unes lletres de salutació, acompanyades d'unes fotografies, atenció que no cal dir com és profundament agraïda» (Massot [ed.] I995: 228).

II $\mathrm{Al} \mathrm{doc.} \mathrm{3,} \mathrm{però,} \mathrm{parla} \mathrm{de} \mathrm{crosses.}$

I2 Ella mateixa comenta a Patxot que mentre era a l'Hospital (és a dir, abans del I9 de juliol de I936, atès que Patxot va haver d'exiliar-se de seguida, primer a França i després a Suïssa) havien parlat de la decisió del seu marit, a qui considerava un mal home (doc. I). 
simbòlica, no solament a Tona (doc. I), sinó ja abans, a l'Hospital de Sant Pau, mentre estava enllitada. ${ }^{13}$

El gener de I938, Palmira tornà a Barcelona i va reprendre les classes a l'Institut Pi i Margall, bé que no li resultava fàcil a causa del fred i de les penúries de la guerra. Totes les seves cartes són un testimoniatge valuosíssim sobre la manca de queviures i el turment dels bombardeigs i de les alarmes aèries, augmentades en el seu cas per les dificultats que tenia a l'hora d'agafar transports públics, de caminar i de protegir-se quan calia, juntament amb els seus alumnes, amb l'agreujant que l'ascensor de l'Institut estava espatllat i hi havia d'anar a peu fins al quart pis. Tot això va anar augmentant al llarg del I938 i al començament de I939, cosa que va donar lloc a una extraordinària descripció dels tres darrers dies de la Barcelona republicana, amb els aldarulls provocats pel saqueig dels magatzems de tota mena de menjar i per la immediata ocupació de la ciutat per les tropes franquistes (doc. 9).

Per altres conductes, sabem que el 24 d'abril de 1937 la Sala Especial de Divorcis de Barcelona havia decretat el divorci entre Palmira Jaquetti i Enric D'Aoust, aleshores professor a l'Escola Normal de la Generalitat. ${ }^{I 4}$ Abans Palmira havia hagut de signar, per indicació del seu marit, uns papers notarials que, a causa de les operacions a què era sotmesa, no acabava d'entendre i havia estat objecte de dolenteries, de males paraules i d'injúries per part d'aquell que, segons ella, li ho devia tot (doc. I). ${ }^{15}$ Per la seva banda, D'Aoust es va tornar a casar, en una data que no coneixem, amb una mestra alumna seva, Carmen Siegrist Ruiz. Més endavant, el I939, fou empresonat, però el I940 va poder exiliar-se, juntament amb la seva segona muller, a Mèxic. ${ }^{16}$

No cal dir que aquest trencament havia resultat absolutament traumàtic per a Palmira Jaquetti, que el I938 va trobar una casa buida, d'on havien desaparegut el cotxe que tenia per al seu marit i un munt de coses materials i espirituals, i si dues mil pessetes s'havien salvat de la crema era perquè eren de la seva mare —amb la qual vivia en aquells moments - i el seu marit no se n'havia adonat (docs. I i 3). En aquestes circumstàncies, se sentia turmentada per la crueltat sense límits, per la dolenteria, per la traïció i per l'egolatria de la persona en qui fins no feia gaire havia confiat (doc. I). Així i tot, havia tret forces de flaquesa, i no solament es dedicava a la recerca de menjar ${ }^{17}$ i a les seves classes, sinó que escrivia, cada vegada més, i havia començat a compondre cançons per a infants, de les quals feia la lletra i la música, al costat de poemes i de poesies curtes, que eren com petites

I3 Va enviar les cançons recollides a Patxot, que les deixà a casa d'un parent a França. Sortosament, no fa gaire la neta de Patxot, Núria Delétra Carreras-Patxot, les va recuperar i va tenir la gentilesa d'enviar-me-les perquè les incorporés a l'arxiu de l'Obra del Cançoner Popular de Catalunya, on tenen la signatura C-290/C-292. No ens ha arribat, però, la correspondència a què sens dubte va donar lloc aquesta tramesa (cf. Massot 2019: 68-73).

I4 Conec aquestes informacions gràcies al Projecte de recerca sobre Palmira Jaquetti, dut a terme per un equip format per M. Àngels Subirats, Josefina Roma, Joan de la Creu Godoy i Salvador Rebés. Barcelona, 20or inèdit.

I5 Vegeu també, sobre aquest tema espinós, Matheu (I972: I74-I75 i I82).

I6 Vegeu l'article anònim i sense data «Henri Daoust» a la Wikipédie francesa <https// fr.Wikipedia.org/wiki/Henri_Daoust> [data de consulta: febrer de 2020].

I7 En cartes successives fa referència constant als paquets de rebia de Patxot, que a vegades no li arribaven sencers, com em consta que passava a mesura que augmentava la fam causada per les estretors de la guerra. 
estrelles en el seu llac calmat (a la superfície) (doc. I). Ja aleshores Palmira anava enllestint el seu primer llibre de poesia, L'estel dins la llar, que apareixeria el mateix any I938 a l'editorial Oasi de Barcelona (docs. 2, 3 i 4), i comptava de publicar també les cançons per a infants a què hem fet al·lusió, que no tiraren endavant (doc. 3). ${ }^{18}$ D'altra banda, els dimecres, que tenia lliures, anava al petit teatre de l'Escola Professional de la Dona, on escoltava una petita orquestra (en la seva prosa tot era petit!) dirigida per Baltasar Samper, que tocava meravellosament música clàssica, moderna i contemporània (doc. I).

En aquells moments tan complicats — des del punt de vista personal i des del punt de vista col-lectiu-, Palmira Jaquetti no oblidava el seu afany de recollir noves cançons. Havia aconseguit, amb la seva tenacitat habitual, un permís de la Junta de Relacions Culturals de la Generalitat de Catalunya per anar a Prats de Molló, al departament francès dels Pirineus Orientals, per continuar-hi cercant el bon material folklòric que ja hi havia trobat abans de la guerra. Quan el va rebre, el curs havia començat i el director de l'Institut no va considerar procedent que abandonés les classes. Es proposava, però, d'utilitzar el permís durant les vacances d'estiu, si es trobava bé, atès que s'havia amagrit molt i se sentia molt cansada (doc. I). ${ }^{\text {I9 }}$

Efectivament, l'I de setembre de I938 Palmira escrivia a Patxot en català des de Prats de Molló (doc. 3), on havia anat fent servir l'autorització de la Generalitat. No hi va anar, però, amb la intenció de recollir-hi cançons, ${ }^{20}$ sinó per refer-se, aprofitant l'hospitalitat d'una amiga, per menjar pa amb mantega, tal com li convenia, per llegir i per somiar. De tota manera, tenia una altra intenció, que ja havia suggerit a Patxot en una carta anterior (doc. 2): anar a Bèlgica per mirar de parlar amb el seu sogre - del qual no rebia notícies - i indagar respecte al passat del seu exmarit, no amb desig de venjança, però sí amb esperit de justícia. Amb tot, a causa de les limitacions de la guerra no disposava de divises i, amb la seva ingenuitat habitual, demanava a Patxot si hi hauria manera d'aconseguir algun camió que l'acceptés. Patxot, com ja devia haver fet altres vegades, li va enviar cinc-cents francs francesos, una quantitat que ella considerava «esbalaïdora» i que, en circumstàncies normals, li hauria permès de complir el seu desig, però ho hagué de deixar córrer perquè va atabalar el seu protector amb noves exigències i se li acabà el temps de què disposava (doc. 4). La cosa fou més greu perquè a l'hora de tornar a Barcelona tingué problemes gairebé insolubles amb el passaport i va arribar un moment que començà a angoixar-se, pensant que la seva manca de puntualitat li ocasionaria un expedient que podia fer-li perdre un lloc de treball que li havia

I8 Aquestes cançons, a les quals Palmira es refereix en cartes successives i de les quals dona una mostra, dedicada als nets de Rafael Patxot (doc. 8), van haver de sortir en espanyol, a causa de la prohibició dels llibres en català dictada per les autoritats franquistes. Vegeu-ne la relació al CCUC (Catàleg col-lectiu de les universitats catalanes), accessible a Internet, $<$ https//ccuccsuc.cat/search $23{ }^{*}$ cat/a?Jaquetti\%2C+Palmira\%2C+I895-I963 search_co$\mathrm{de}=\mathrm{a}>$ [data de consulta: febrer de 2020]. Palmira Jaquetti s'hi refereix a Matheu (1972: I83-I84 i I87).

I9 Ja havia pogut donar notícia d'aquest permís a Massot (2004b: I84), però en aquell moment no sabíem si Palmira l'havia pogut utilitzar.

20 Cap al Io de setembre, però, va tenir l'oportunitat de trobar-hi tres cançons, conegudes per una dona del Principat que havia anat fet una visita ràpida a Prats de Molló per veure una filla que hi treballava de minyona (doc. 4). 
costat molt d'aconseguir, i es queixava que al llarg de la seva vida mai no havia tingut un goig que no se li girés i li costés llàgrimes (doc. 5).

A l'hora de la veritat, tanmateix, no va passar res: el 27 d'octubre Palmira tornava a escriure des de Barcelona a Patxot, altre cop en francès, i li explicava que tot estava resolt i que no havia de témer cap sanció del Ministerio de Instrucción Pública, del qual depenia el seu Institut (doc. 6). Ben aviat, però, li caurien a sobre un seguit de problemes gravíssims, que ja no explica a la correspondència que ens ha arribat. ${ }^{21}$ La victòria de l'exèrcit «nacional» va implicar el tancament de l'Institut Pi i Margall i Palmira Jaquetti, com la resta de mestres i professors, va ésser sotmesa a un sever expedient de depuració. Ella, que oficialment encara pertanyia a l'Institut de Reus, en va sortir el maig de I94I, amb un resultat relativament benigne: no fou expulsada ni traslladada forçosament, com tants dels seus companys, però sí que fou inhabilitada - per un temps no especificat- per a càrrecs directius i de confiança, i castigada amb la pèrdua dels havers deixats de percebre (González-Agàpito i Marquès I996: I64). Segons la documentació aportada pel Projecte de recerca que ja hem esmentat, al final de I939 fou adscrita a l'Institut Verdaguer de Barcelona i l'abril de 1942 passà definitivament a l'Institut Montserrat, també de Barcelona, on romandria fins a la seva mort, causada, el maig de I963, per un accident de cotxe que acabava de tancar una vida plena de tragèdies.

Mentrestant, Palmira havia continuat escrivint, obtenint alguns premis i assistint a conferències i actes que proliferaven a Barcelona, sovint d'una manera amagada o semiclandestina, i fins i tot va participar en alguns congressos internacionals i va fer una conferència a l'Institut d'Etnografia de Ginebra, on tractà una vegada més de les seves estimades cançons populars (Matheu I972: I75-I79 i I85-I88; Cardona I964).

Malgrat les dificultats de la postguerra, no va deixar tampoc de banda la seva tasca de col-lectora de cançons, amb una brevíssima «missió voluntària» feta el I940 a Setcases, Manyanet, Anglès i la Vall d'Aran, que devia enviar ella mateixa al senyor Patxot, ${ }^{22}$ i amb un extens recull de 439 cançons que aplegà el 1945 a set asils de Barcelona, per al Consejo Superior de Investigaciones Científicas, dins l'ambiciós projecte de mossèn Higini Anglès. ${ }^{23}$

Palmira Jaquetti va morir preocupada, amb tota la raó, perquè els deu mil documents que havia aportat a l'Obra del Cançoner Popular de Catalunya no solament no havien estat publicats, sinó que, a conseqüència de la guerra i de les posteriors desavinences entre l'Orfeó Català i Rafael Patxot, havien quedat repartits entre Barcelona i Suïssa i eren totalment inassequibles. Eren inèdites igualment les extenses i intenses memòries que havia anat escrivint durant les seves missions, i ni tan sols en va poder aparèixer la primera, prevista per al volum IV de Materials, que va quedar pendent el I936. Per sort, d'aleshores ençà les coses han

\footnotetext{
2I Després del doc. 9, del gener de I939, només s'han conservat quatre targetes postals de Palmira Jaquetti a Patxot, dels anys I940, I94I i I942, sense informacions rellevants a causa de la censura, i la còpia mecanografiada d'un poema titulat «Beatitud», feta «per el Senyor Rafael Patxot set[embre] I958».

22 Es conserva a l'arxiu de l'Obra del Cançoner Popular de Catalunya i en va aparèixer una mostra a Massot (2010: 265-275).

23 Vegeu el web Consejo Superior de Investigaciones Científicas. Fondo de Música Tradicional, Misión Mı2, <https://musica tradicional.eu/cn/sources/I30>, minuciosa obra d'Emili Ros [data de consulta: febrer 202O].
} 
canviat molt. L'arxiu de l'Obra del Cançoner Popular de Catalunya ha estat recuperat gràcies a la generositat dels nets de Rafael Patxot i, amb el suport entusiasta de l'actual Direcció General de Cultura Popular de la Generalitat de Catalunya, ens ha estat possible de digitalitzar-ne tot el contingut i de publicar totes les memòries de Palmira Jaquetti, acompanyades d'una àmplia selecció de les cançons recollides en cada una de les missions. Això ha permès que un bon nombre d'estudiosos s'hagin interessat per aquestes missions i per la seva col-lectora. L'any que ara s'inaugura, impulsat per la Direcció de Cultura Popular de la Generalitat de Catalunya, permetrà sens dubte de donar una nova empenta a tota mena de recerques referents a Palmira Jaquetti, que si no va ésser la primera col-lectora de la cançó popular catalana, ni l'única dona que va intervenir en l'Obra del Cançoner Popular de Catalunya, sí que va ésser la que va treballar amb més dedicació i amb més entusiasme en aquest camp, i això sol la fa mereixedora del nostre agraïment i ens estimula a seguir-ne les petjades.

\section{$\operatorname{Textos}^{24}$}

\section{Carta manuscrita, Barcelona, 3 de gener-març de 1938}

Barcelone, le 3 janvier-mars 1938

(Avenue Sabí d'Arana, I, $4^{\circ} 2^{\mathrm{a}}$ )

Très cher Monsieur,

Je sais que vous serez très heureux d'apprendre quelque chose sur ma santé. Moi-même, je n'aurais jamais cru qu'un jour, je serais en état de marcher comme je le fais. M. ${ }^{\mathrm{r}}$ Vilardell ${ }^{25}$ a sculpté mes deux genoux, m'a mise dans le plâtre, m'a opérée six fois; il a fait de mes genoux un chef d'oeuvre, il m'a rendu le mouvement et j'oserais dire, la vie. Je n'ai qu'une canne, pas tout à fait une béquille, mais je dois être toujours accompagnée et je dois m'appuyer sur un bras. Je me tiens chaque jour davantage, j'ai même essayé, à Tona, où l'on m'a portée le mois de juillet, à ma sortie de l'Hôpital, j'ai même entrepris un de ces travaux qui occupaient la plus grande partie de mes étés, vous le savez bien, et j'ai réussi à y trouver quelque chose. Je me rappelais que je vous l'avais promis, et j'étais bien contente de pouvoir essayer mes premiers pas, les premières marches que j'ai pû monter, chez les gens du peuple qui n'ont rien étudié mais savent bien des choses.

A présent je fais toujours ma classe à l'Institut, je monte jusqu'au 4ème étage, (car l'ascenseur ne va plus depuis longtemps[,] je grimpe (!) sur l'autobus, et j'ai trouvé dernièrement quelqu'un qui me prête une auto pour le retour, car il fait si sombre, et c'était un grand danger pour mes jambes presque raides.

24 He respectat escrupolosament aquests textos, manuscrits en una lletra sovint difícil i a rajaploma, en català i en francès, sense canviar-ne l'ortografia ni la puntuació. Alguna vegada, a fi de facilitar-ne la lectura, hi afegeixo comes o punts entre claudàtors, com també faig si falta alguna lletra. He respectat també l'accentuació dels originals, algunes vegades incorrecta, tal com marco en nota. Indico també algun altre lapsus de l'autora, sense entrar en detalls que ara resultarien fora de lloc. Quan m'ha semblat convenient, afegeixo també en nota la identificació de personatges o alguna altra qüestió que m'ha semblat interessant i que no figura dins la introducció.

25 Josep M. Vilardell, director del Servei d'Ortopèdia de l'Hospital de Sant Pau de Barcelona (cf. Calbet-Corbella I983: I68). 
Je n'ai qu'un tout petit jeu. Je suis bien contente d'être utile et de pouvoir gagner ma vie, car de grands malheurs ont suivi les quelques entretiens que j'ai eus avec vous à propos d'une certaine personne. L'auto n'est plus dans mes mains et grande quantité de choses matérielles et de l'esprit ont été enlevées pendant mon absence de trois ans presque. Je n'ai plus retrouvé mon foyer. Il était disparu, il était ailleurs. J'avais même signé quelque chose, le lendemain de ma dernière opération au pied, et depuis cette période, je n'ai reçu que des méchancetés, des ordures, des injures, de la part de qui a tout reçu de moi, et avec tout ce qu'on peut attacher au mot tout, il avait tout mon cœur sans réserves, sans défaillance, sans mensonge, sans bornes.

J'ai été bien éprouvée, croyez-le ; ce n'étaient pas les tortures phisiques ${ }^{26}$ qui me faisaient le plus souffrir. C'était la cruauté sans pareil et aussi sans bornes, c'était la méchanceté, la trahison, l'égolatrie ${ }^{27}$ d'autrui, qui faisait mon tourment et ma détresse. Et voyez. Je suis issue de l'Hôpital, où j'ai été portée par lui, où j'ai soutenu ma maison et les expositions et les peintures et les autos et les stais ${ }^{28}$ et tout le reste, l'atelier, etc, (car j'ai toujours eu mes appointements, je les ai toujours conservés) je suis sortie toute seule, et j'ai dû m'habituer aux affreuses douleurs qui me causaient les mouvements des genoux, et j'ai dû me chercher une vie, qui, avec la guerre, c'était ${ }^{29}$ rendue très difficile même à ceux qui avaient deux jambes comme tant de monde. Bien que mal, je me tire de tout. A présent, on doit opérer maman un de ces jours. C'est un peu délicat, et des suites des dernières couches, il y a plus de 25 ans - Puis, on doit aller à la chasse de la nourriture, puis il y a mes classes - Je me tire d'affaire parce que j'ai appris à souffrir, j'ai eu de longues années d'apprentissage, et puis je suis toujours simple et enfant, quoique je ne puis plus voler avec les jambes. Je sais me contenter, mais je sais, plus que jamais, voler dans les immensités du rêve et de ma liberté apprivoisée. Ma liberté tout de même, forte, vigoureuse, taillée et polie par le courant de ma vie et par bien des larmes, ces larmes de la souffrance, qui seules, savent briser les chaînes les plus fortes. Je me suis mise aussi à travailler, avant votre départ, j'écrivais déjà beaucoup. La dernière fois que vous avez été me voir, et que malheureusement on m'avait descendue aux courants galvaniques, et bien, cette fois si s'avais eu la chance de vous voir, je vous aurais déjà lu quelque chose. Mais depuis lors j'ai beaucoup écrit, j'ai versé mes malheurs, la profondeur de ma tragédie, en beauté. J'ai beaucoup râturé, ${ }^{30}$ refait, mais aussi beaucoup écrit qui a peut être quelque force et quelque delicatesse. ${ }^{3 \mathrm{I}} \mathrm{Je}$ serais bien aise de vous en faire connaître quelque chose, si cet été, il était possible de vous revoir, et Mr Carchas et Mme Boufré. ${ }^{32}$ Dernièrement et depuis bien des mois, je travaille dans des chansons d'enfant dont j'ai composé la mélodie et la poésie, j'en ai déjà une grande quantité. Sans cela je travaille à des poèmes et à de toutes petites poésies, de petits joujoux qui sont comme de toutes petites étoiles dans mon lac calme (à sa surface).

\footnotetext{
26 Lapsus per physiques.

$27 \mathrm{El}$ mot francès correcte seria égotisme.

28 Deu tractar-se del mot anglès stay.

29 Lapsus per s'était.

30 Lapsus per raturé.

3I Lapsus per délicatesse.

32 No sé a qui es deu referir.
} 
Puis il y a la guerre, qui me fait beaucoup souffrir par ces froids si durs, comment ils doivent souffrir, nos pauvres soldats! C'est horrible, quand on pense à la profondeur du mal et du malheur!

Les mercredis je ne dois pas aller au Lycée, donc, je puis disposer de mon temps, et je vais entendre des répétitions qui ont bien lieu dans le tout petit théâtre de l'Ecole Professionnelle de la Dona; c'est un petit orchestre dirigé par Mr Samper ${ }^{33}$ et ils jouent merveilleusement. C'est un oasis que ce petit coin où l'on gèle, mais où l'on peut entendre Haëndel, ${ }^{34}$ Bach, Mozart, le xvi et le xvii s, ${ }^{35}$ les musiciens modernes comme Roussel et la dernière école française.

Je n'ai pas fait de convalescence. Je suis rentrée à l'Institut et repris ma besogne en même temps que j'obtenais la permission, et decernée ${ }^{36}$ par la Junta de Relacions Culturals Generalitat Catalunya, d'aller en France, à Prats, dans les Pyrénées Orientales, pour y chercher les mêmes étoffes de l'esprit que j'y avais déjà cherché. Malheureusement, cette permission m'est arrivée trop tard. Le cours était déjà commencé, et Mr le Directeur a trouvé que c'était dommage. Si je puis me soutenir jusqu'aux vacances (j'ai beaucoup maigri, même trop, et je suis déjà fatiguée) je chercherai moyen d'aller entreprendre mon travail et dans ce cas-là j'espère vous voire tous.

Pendant ces courtes vacances, du I au 8 de janvier, je voulais aussi m'en aller. Mais il y a maman, puis la difficulté d'être accompagnée jusqu'à Perpignan, où mon amie de Prats ${ }^{37}$ serait venue me chercher.

C'est dur pour moi, c'est le 4ème automne que je dois rester enfermée, et pour ma santé ce serait si précieux de partir!

Tous ces longs mois, et ma lettre qui ne parle que de moi, est trempée de votre souvenir et de celui de ces chers amis dont je vous parle.

Veuillez m'écrire ou me faire savoir de vos nouvelles.

Votre respectueusement dévouée, Palmyre Jaquetti.

\section{Carta manuscrita, [Barcelona], 25 de maig de 1938 (amb una llarga addenda no datada)}

Très cher Monsieur! Ce 25 mai I938

Voilà encore une fois, c'est la troisième, que je tache ${ }^{38}$ de vous envoyer de mes nouvelles. Mes lettres m'ont été toutes remises avec le "non reclamé »,39 et moi qui suis si pressée de vous dire grand merci de vos trois envois qui aident si fort ma santé pas tout à fait satisfaisante, à présent! (car j'ai trop maigri et endure de persistants ensomnies).

33 Baltasar Samper, compositor i gran col-laborador de l'Obra del Cançoner Popular de Catalunya, que aviat s'hauria d'exiliar i que també rebria ajuda de Patxot (vegeu Massot 2020a).

34 Lapsus per Haendel o bé Händel.

35 És a dir, siècle.

36 Lapsus per décernée.

37 Probablement es refereix a Madame Cholerton, que l'acollí generosament a Prats de Molló (doc. 3).

38 Lapsus per tâche.

39 Lapsus per réclamé. 
Moi qui voudrais tant savoir quelque chose de vous et de Mme Boufré, $4^{\circ}$ cela me ferait un grand plaisir d'avoir une réponse. Aussi, comme je jalouse mes lettres, qui se sont promenées à travers l'Europe, où j'aurais bien voulu les suivre et faire un tour qui mit un peu d'air dans mon esprit. A présent je marche beaucoup mieux, mais je n'ai pas pu trouver une voiture et je grimpe sur l'autobus, mais ne puis aller que là. Les trams, ce n'est plus pour moi, ces raisins d'où il coule des grains d'humanité tout autour, tout à fait comme une grappe. Mais le cours va bientôt finir et j'ai l'espoir de pouvoir aller un peu quelque part. J'aimerais bien que ce soit en France. L'air serait différent et j'aurais plus de facilité pour nourrir mon âme un peu malade.

Je viens de voir Mr Barbe, ${ }^{4 \mathrm{I}}$ qui est venu chez moi. Je vais donner un volume de poésies qui paraît la ıère quinzaine de juin. Je voudrais vous en envoyer un. Aussi, je publie des chansons d'enfants, et $\mathrm{Mr}$ Bache ${ }^{42} \mathrm{~m}$ 'a rendu un grand service en les lisant soigneusement et en me donnant son honnête appréciation. Je crois qu'elles peuvent rendre un grand service aux enfants, pas seulement mes chansons, mais n'importe quelles chansons qui seraient écrites pour les enfants, rien que pour eux, au pont de vue du sujet, des éléments poétiques et mélodiques et du nombre de strophes. Je tâche de m'appliquer chaque fois davantage, à être utile à tous, et dans ce travail j'ai bien l'occasion de vider le trop plein de mon âme, pas en amertume, mais en joie.

Maman est bien mieux. Elle marche déjà assez bien. Moi, que vais entreprendre tout de suite une suralimentation, je m'appliquais à manger davantage mais je vois que ce n'est pas ça, car les digestions deviennent difficiles et la nuit mon esprit en éveil travaille et se fatigue même quand je réussis à dormir.

Puis, à côté de mes propres souffrances il y a celles qui nous sont fournies par la guerre. Les bombardements, la queue, le manque de tant de choses.

Comme vous avez été délicat! Je vous suis très reconnaissante, j'espère pouvoir me refaire un peu, je suis dans les os, pas faute de manger, car j'ai mangé, pas comme avant, mais assez bien, depuis que je suis sortie de l'Hôpital; mais les chagrins, la dernière épreuve, la plus forte de ma vie, qui a commencé à avoir lieu pendant mon séjour à l'Hôpital, mine et a miné ma santé. On n'efface pas facilement dix, douze années, quand c'est justement où l'on avait mis tout le rêve et la flamme la plus puissante. ${ }^{43}$ Mais c'est de là d'où jaillit cette source de poésie qui ne tarit pas et qui n'est loin d'être triste.

Le livre qui va paraître est tout récent, ce sont des poésies qui chantent, en quelque sorte, les travaux de la femme au ménage, la douceur du foyer, la lumière. Il a comme titre «l'estel dins la llar».

C'est une joie que je voudrais bien pouvoir vous offrir, et à Mme la Directrice et à Mr Charcas aussi, de ma propre main. En attendant, je vous répète notre gra-

40 Potser es refereix a la muller de Rafael Patxot, amb la qual Palmira Jaquetti tenia també bona relació.

4I Es tracta d'un nom que va sortint en diverses cartes, fins i tot a les escrites en català. Gràcies a la generositat de Salvador Rebés, que m'ha passat les cartes de Palmira Jaquetti adreçades a Carles Riba, he pogut arribar a la conclusió que parla de Riba, amic també de Patxot.

42 Es tracta sens dubte del mateix nom, escrit de tres maneres diferents en poques ratlles. 43 Al-lusió al seu matrimoni fallit amb Enric D'Aoust. 
titude et notre vif souvenir, en même temps que je souhaite bien ardemment que ma lettre vous trouve, où que ce soit.

Bien à vous, Palmyre Jaquetti

Je reprends ma lettre, que j'avais rédigée il y a bien longtemps. Pendant ce temps on a operé 44 maman, qui, à présent, est déjà chez nous, pas très bien, car nous avons eu le malheur qu'elle a eu un nerf piqué des suites de l'anesthésie aux reins.

Il y a quelques mois, j'ai écrit à Mr Praph, ${ }^{45}$ et ma lettre s'est un peu promenée inutilement, et est revenue comme un oiseau qui regagne le foyer après un long voyage.

Je le regrette et vous charge, si vous avez l'occasion de le voir, de le saluer bien affectueusement de ma part, ainsi que sa famille et son enfant.

J'écris toujours des chansons et des poèmes, j'ai été longtemps refoulée, et maintenant c'est un jaillissement intarissable. Puis, voilà le retour du printemps, qui peut bien m'excuser, mais c'est mon propre printemps, mon paysage à moi, mon cœur, ma lumière. Il y a très peu de souffrance, dans ma poésie. Cela reste au fond, comme la fente de ma propre source, comme la blessure inguérissable par où se verse mon esprit avide de vie et de lumière.

Aujourd'hui, j'ai parlé de vous à Mr Barbe, je ne l'avais plus revu. Seulement, il était venu à l'Hôpital, avant la guerre. ${ }^{46} \mathrm{Il}$ est bien mieux, quoiqu'il a neigé sur sa tête. Puis, il a des lunettes, vous en savez peut-être quelque chose, de ses pauvres yeux.

Je voudrais charger Mme Boufré d'une comission ${ }^{47}$ auprès de mon beau-père, en Belgique, où il me faudrait quelqu'un qui me justifie, qui parle de moi. Je leur ai écrit une longue lettre par l'entreprise du consul, ils n'ont répondu un seul mot, ni à mon issue de l'hôpital. J'aurais besoin que quelqu'un qui me connaît parlât de moi là-bas. C'est à Verviers, - Stembert, 3, rue de la Chapelle. Peut être elle voyage de ce côté, je ne désire rien, aucun succès pour moi, mais une position digne et propre. Envoyez-moi de vos nouvelles. B[ien] à vous. Palmyre Jaquetti.

\section{Carta manuscrita, Prats de Molló, 1 de setembre de 1938}

Sr. R. Pat-Joubert. ${ }^{8}$

Prats de M. I de set. $1928^{49}$

Respectadíssim i preuadíssim senyor! Acabo de rebre la seva. El mal que m'ha fet l'ensorrada de les meves il-lusions queda atenuat per l'esplendidesa d'aquest dia meravellós, tot esclat, amb les cimes de Costabona perfilades i florides de la neu d'aquests dies; prenc la muntanya de la mà dels meus somnis i aixeco al blau

44 Lapsus per opéré.

45 Es refereix sens dubte a Rafael Patxot.

46 Curiosament, Jaquetti havia parlat al fragment anterior d'aquesta carta del senyor Barbe, que havia revisat els seus poemes dedicats als infants.

47 Lapsus per commission.

48 És a dir, Rafael Patxot i Jubert.

49 Lapsus per 1938. 
immarcessible ${ }^{50}$ tot un ram de clavells blancs en ella. Sí, m'ha frapat ${ }^{51}$ perque $^{52}$ ambicionava més en la meva set de justícia i en la gran solitud en què visc. Volia una cosa que em caldria de gran necessitat. Anar a Verviers, a Bèlgica. ${ }^{33}$ Tinc el meu passaport belga reglat i visat com és degut, però no tinc diners, ni un sol cèntim francès ni belga, ni manera d'obtenir-ne, amb els diners espanyols, ni diners espanyols que m'ho permetin, ni és lícit treure cap diner de cap mena, d'Espanya. Així he marxat amb 7 pts i 20 francs, obtinguts, aquests, per gran favor.

El temps que passa cada vegada va allunyant més la meva possibilitat d'anar a aclarir i conèixer moltes coses que tinc por, ignorant-les, que em facin perdre la raó. No exagero, disminueixo i dissimulo el meu estat moral i tants d'esforços hi faig que des d'ara el callaré per a sempre a tothom, però voldria ardentment reeixir a cercar els mitjans justificatius de la justícia que emprendré, pel meu compte sol, si, com fins ara, ningú d'allà baix no m’hi ajuda, i es limiten, només, a girar el cap per no saludar qui consideren un monstre. Però em deixen, com m'han deixat, sola per sortir amb crosses i algú que em portés, a cercar la meva llar saquejada i perduda, des d'un hospital on, amb el meu coll sempre sostingut ajudava la vida material, la sostenia tota i feia totalment la vida de l'esperit d'algú que amb engany i traïdorament, valent-se del meu estat de tres anys al llit, em féu firmar papers que em duran a morir-ne de pena, si Déu no hi posa remei. ${ }^{54}$

No sabria d'algun camió on pogués cabre (sóc molt prima i torno a ésser agilíssima de cames) per anar allà dalt? No duc equipatge, tota la meva roba cap en un saquet flexible que pesa $2 \mathrm{Kg}$, potser, escassament. Pujo al camió jo sola per alt que sigui, com sola enterament he pujat i baixat de trens i autos. A casa, sense tranvies ${ }^{55}$ possibles ni cotxes, de vegades tinc sort d'un camió ben tronat el xofer del qual és l'únic que es detura i m'accepta, dels 40 o 50 a qui he fet senyal amb el bastó, i així torno a casa, si de cas m'ha estat urgent d'anar a algun lloc i m'he deixat temptar, car ja sé que no hi ha res per a mi, ni tan sols un cotxe que em dugui a l'Institut, on no manco un sol dia, malgrat els bombardejos horribles que permeten de córrer, al menys, als altres i no a mi, cap al refugi. Quan jo hi arribaria tot fóra ja ensorrat.

No voldria donar a la meva lletra el to d'un plany, és una joia molt alta per a mi, d'escriure-li, i només li diré encara una cosa que penso: Ara no tinc cotxe, el meu també m'ha estat pres per la mateixa mà que se n'ha endut tota la resta, però és ara quan jo el necessitava. Fa quatre anys que estic immòbil, els meus turments morals són semblants als que he passat en el cos; necessito, de gran urgència[,] un repòs, per aquesta terrible sotragada, que em fóra proporcionat justament pel moviment. La primera cosa es ${ }^{56}$ de comprar-me un cotxet, hi empraré tots els meus guanys i energies. Ja el tindria, però des de la Conselleria de Cultura em van instar

50 És a dir, immarcescible.

5I Gal-licisme per colpir o impressionar.

52 Lapsus per perquè.

53 Com diu a la carta anterior, era el lloc on vivia el pare d'Henri D'Aoust.

54 Referència a Henri D'Aoust, que, com ja hem vist, li va fer signar uns papers amb vista al divorci que ell desitjava.

55 Lapsus per tramvies.

56 Lapsus per és. 
molt que no ho fes ara, perque ${ }^{57}$ "me'l prendrien" (i fóra el $4{ }^{\text {rt }}$ que compro amb les meves suors i perdo). Ara, que cal dir que no m'han proporcionat res per anar i venir de classe, i que cada dia n'he embotit a l'autobús amb perill de la vida i amb una hora de cua que ha exercitat moltes coses en mi, i també m'ha enfortit, a còpia de dolors terribles, els genolls.

Si, en un temps més o menys llunyà en què regnés la pau hi hagués una ocasió i fos possible d'adquirir-lo, un cotxet, jo el pregaria de sortir-ne fiador i d'adquirir-lo.

Tinc 2000 pts, tota la nostra fortuna, són estalvis de la meva mare i per això no han estat robats, com tota la resta de valor, car no en tenia notícia, l'home sense cor ni consciència que fou capaç de tant. Estalviaré i donaré lliçons, fora de la meva paga, per arribar a pagar-lo. Ara aprendré jo mateixa de guiar, però tinc ja pagats els estudis a una noia. Si pogués moure'm, aniria fent-se'm comportívol aquest gruix de tragèdia de les meves coses. Ara mateix ja penso amb terror en el retorn, forçós perque ${ }^{8}$ l'estiu avança.

També desitjaria que em parlés del meu llibre. ${ }^{59}$ He rebut totes les seves postals i carta que he rellegit infinitat de vegades. La carta m'ha acompanyat com un tresor, tan plena de sentit i tan densa de fortitud moral, de senyoriu de l'ànima, tan catalana i tan valenta. Jo escric sempre en francès per a merèixer més facilitats de la censura, en el sentit de rapidesa i europeïtat. Per aquesta carta he tingut les úniques notícies de Frau Guths, ${ }^{60} \mathrm{i}$ he pogut transitar, com ho faria ara per la muntanya, per les cimes on plana la gran fortitud i elevació espiritual de vostè, la carta venia a enfortir-me, a sustentar-me, a péixer el meu esperit, com d'una manera meravellosa és alimentat el meu cor, que, mancat completament de l'energia necessària a les cues i a les baralles i lluites a mort per un mos, ja hauria sucumbit, com també el de la meva mare operada de poc, si no fos aquesta providència de taumaturg llegendari que deixa tan sovint, a nom meu, un paquet del que és ja prehistòric a casa nostra, d'aliments!

Els he rebuts tots, els paquets, i bastant sencers. Petites picardies, en un temps de gana i de desori, són massa explicables perque ${ }^{6 r}$ no les excusi, tot i lamentar la pèrdua d'alguna cosa necessària. Amb 5 pans, magnífics, insospitats de grossos i savorosos, ${ }^{62}$ la meva mare va poguer ${ }^{63}$ menjar una cosa que li és molt convenient ¡sopa! i que no pot menjar mai.

Jo ara m'atipo (aquest és el mot just) tant com puc i deixo el meu lloc perque ${ }^{64}$ la meva mare es refaci una mica, allà baix. Menjo mantega, l'aplano goludament damunt un pa blanquíssim, de temptadora flexibilitat i perfum. Aquella olor de pa, de benedicció de vida que feien les fleques, en la prehistòria inconscient de la felicitat ciutadana! Ara un forn fa tuf de cua humana i de baralles que predisposa ben poc a la poesia.

57 Lapsus per perquè.

58 Lapsus per perquè.

59 L'estel dins la llar, únic llibre de poemes publicat per Palmira.

6o Persona que no sé identificar.

6I Lapsus per perquè.

62 Lapsus per saborosos.

63 Lapsus per poder.

64 Lapsus per perquè. 
Vaig escrivint. Ara sortiran dos llibres de cançons d'infant i un de poesia amorosa, sana i forta, de gust de llar i de vida que ara fa just un any que començava.

La crítica ha rebut molt bé i amb elogis molt alts aquest primer llibre. Jo vaig fent. Em veig madura ja d'experiències, com diu Rilke, la poesia surt d'aquesta superposició d'experiències, brolla, fresquíssima, com aquest Tec que em canta a cau d'orella.

Reïxo, sola, a pujar i baixar per una pendent d'uns $35^{\circ}$, a passejar-me pels prats plens de sorpreses d'aigua i alts i baixos, i amb herba fins al genoll, que és doble dificultat. A travessar i passar pels rierols que voregen els rius, tot delícia d'aigua i pedres. A cada moment m'admiro de mi mateixa i vaig enfondint les meves meditacions. Ja no necessito l'ajuda de ningú! Vaig sola a passejar! Sola! Abans no sabia què volia dir no haver de menester ningú per moure un peu. Ara sí que ho sé!

Torno a insistir en la meva necessitat d'anar a Bèlgica, si hi hagués manera de qualsevol cosa modesta. Aniria sola, ara ja en sé i puc.

Mme Cholerton ${ }^{65}$ és un gran cor, una dona cultíssima, un esperit com no se'n troben gaires, a qui dec aquest oasi d'abundor i meravella en què visc per uns dies. A mitjans de mes hauré de pensar en el retorn, ai! on la vida és un atzar i una dada d'un problema de probabilitats.

Però queda l'ànima i la poesia.

El pregar de saludar tots els seus, la s[eva] s[egura] s[ervidora] Palmira Jaquetti.

\section{Carta manuscrita Prats de Molló, 10 de setembre de 1938 (amb una addenda sense data, amb un poema dedicat a Rafael Patxot, datat el} 6 de juliol de 1938)

Sr Rafel Patxot Joubert

Prats [de Molló], Io set. I938

Honoradíssim senyor! acabo de rebre de la seva generositat, la suma esbalaïdora de 500 fr. francesos. Això obre tot seguit la perspectiva del viatge cap al descobriment de la veritat, fet per mi mateixa, ja que ningú havia respost a la meva crida desesperada - Vull justícia, justícia, no per a venjar-me, ni per a punir, sinó per a saber, saber, la veritat, la llum, en el meu cor, i calmar-me. He aconseguit la pau escrivint. Així que prenc un llibre, (ací he començat seriosament a llegir, després d'anys de no haver-ho pogut aconseguir, i devoro, ara) encara, com abans, potser no tant, cada mot és un parany cap als meus propis pensaments. De vegades em trobo, al cap d'una estona d'abandó total de la lectura, aparentment, llegint, totalment abocada a camins i persones, imaginant situacions precioses, coses passades, o futures. Aquest llarg exercici de la meva imaginació, present o futura, car de vegades imagino el que m'imaginaria, ho tinc per una malaltia, per una ja morbositat que no goso explicar a ningú i que no crec gaire que hi hagi metge capaç de curar, car he arribat també a un gran escepticisme pel que fa a l'eficiència mèdica en la patologia de l'esperit. Crec, i ho crec damunt del meu cos natural, en l'estisora i en el bisturí. El Dr Josep M. Vilardell ha esculpit els meus genolls de cap i de

65 No tenim cap altra referència d'aquesta persona. Més endavant (doc. 5), Palmira se'n queixa perquè no ha sabut fer les gestions adequades per resoldre el tema del seu passaport belga. 
nou i l'un l'ha pogut deixar com era abans, deforme, i l'altre en condicions de fer un bon xic de joc, lo qual és molt. Ell, i el dolor de l'ànima llatzerada són els meus recreadors. A ells dec la vida que ara meno, però vull treure'm aquest sofriment que em mata, ja que no hi ha gent de paraula i que a casa nostra tot és absorbit per la tragèdia col-lectiva i a l'igual d'altre lloc més a l'orient, no hi ha temps ni energies aplicables a cap particular, que d'altra banda no existeix. Tot és degut al formiguer, res a la formiga. I com que jo em veig amb una vida, viva i amb una ànima plena, com sempre, de set d'infinit i d'amor, vull, no allò que en diuen viure la pròpia vida, (que conec de la vora, per desgràcia) vull viure-la en la netedat i en la claror, al sol, de cara i d'ànima a la creació, tan bella, tan mesurada i perfecta.

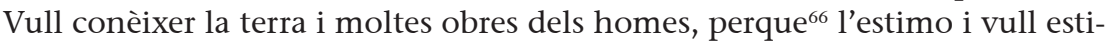
mar-la més encara. Vull alçar-me més i més i contínuament de la terra xopa de sang, on tants hi xipollegen, de la terra senzillament fangosa que jo vull per a pastar-la i dur a Déu l'obra, la que sigui, tan perfecta com pugui, dels meus dits d'infant, no per a arrossegar-hi els peus i esquitxar-ho tot, i tapar les estrelles. Voldria abastar les estrelles, els mons infinits de sonoritat inextingible. Voldria arribar al cor de l'ànima del gran sord, voldria ressonar de cantúries, com ell, però sense orgull.

Em vull petita, ben petita, m'adono que ho sóc i sé que només és aquest el llum que em pot dur cap amunt. Però tot, dins meu, és massa impregnat d'aquesta bona fe i d'aquest amor que vaig posar en un home; vull saber, ara, qui és, qui era, ben independent del que ell mateix m'ha dit. Si tinc motius de lligar les dues coses i d'absoldre'l, sóc prou generosa i prou comprensiva per a fer-ho.

Després, ho deixaré en repòs. Però aquest any ha estat una dura prova, confinada, per l'horror de tot, pel bombardeig, per les meves cames, per la manca de vehicles on jo pugui pujar (els tranvies ${ }^{67}$ són raïms humans), per la gent, que també he de fer-me càrrec del calvari material i sovint moral que passen, (però l'infant que hi ha dins meu es fa poc càrrec quan es sap capaç de fer, ella, pels altres, tot és cosa de voler-ho) tot ho he posat en joc, tot m'ha fallat, fins a posar-se'm malalt l'advocat jove que per fi havia reeixit a trobar, M[aurici] Serraïma, ${ }^{68}$ que primer, fou, durant mesos, a la torre. ${ }^{69}$ Tot en contra. He de fer salvetats. Per exemple. El Sr Barbe, que, malgrat vista defectuosa, com ja sap, ha vingut molt sovint a casa per revisar les meves cançons, ja que a mi se'm fa ja impossible d'anar en tranvia..$^{70} \mathrm{No}$ oblido pas tan gran favor i fet amb tanta gentilesa i tanta bondat.

També, quan ja no hi havia cues a fer, car ja no s'obté res, l'arribada dels paquets de vostè han estat el sosteniment de casa nostra i de tothom que he pogut ajudar, de la mateixa manera que vostè ho feia i pensant joiosament en vostès.

Ara m'atipo tant com puc de mantega i de pa i estic contenta perque ${ }^{71}$ ja he guanyat una mica. Vull tornar preparada al dejuni final, que deurà ésser horrorós, si en sortim amb vida. A més, a casa, la meva mare i la noia (obligada pel nostre

66 Lapsus per perquè.

67 Lapsus per tramvies.

68 Deu voler dir Serrahima.

69 Es deu referir als dies que Maurici Serrahima va passar a la presó, acusat d'espia. Serrahima (I98I) no fa cap esment de Palmira Jaquetti.

70 Lapsus per tramvia.

7I Lapsus per perquè. 
estat) ara poden menjar més, tenen el meu pa i també es preparen per més tard, per l'hivern.

Però, tornant al que deia, he vist de la vora la covardia dels (m'ho vol deixar dir?) senyors, que tenen una por terrible de comprometre's, però si s'hagués tractat d'algú que no tingués tanta raó com diuen que tinc sense que ho demani, no sé què haurien dit i fet perque ${ }^{72}$ hi ha coses que no poden deixar-se així, cal una sanció, una justícia no sols en el comportament extern, de fórmula, sinó en el de l'amistat, de la relació pura, del cor. Puc dir que no he pas estat gaire encoratjada al moviment, i m'he mogut. Només he obtingut, d'una amiga que fou retratada llavors de l'exposició, i que aleshores no tenia inconvenient a visitar el taller per a tal objecte, la negativa d'anar a dir res, ara, car és casada i el marit "no vol que el visiti perque ${ }^{73}$ el detesta i menysprea["]. Bé. El consol final fou: "a tu t'ha fet falta el teu pare... Ell l'hauria assassinat”. Cal dir res més de la caritat tan poc cristiana dels nostres coetanis? Amics, amics. Mentides ornades de fullaraca. Quan en trobo un, per alt que sigui, dic i diré "res no és perdut, encara, al món[“]. Tot hi és. Les essències més pures de la vida es mantenen en aquesta sal. Permeti'm, doncs, de reduir vostè a sal. Sal en francès.

Ara vaig a la primera idea. Aniré a Bèlgica, amb aquests diners. Però si hi havia algú, allà a Bruselles, ${ }^{74}$ per ex., per acompanyar-me en un cotxe, les coses anirien millor i més depressa ${ }^{75}$ i no m'exposaria tant, tota sola. Conec molt bé tot allò, hi he estat moltes vegades. Es tractaria de tenir la confiança i l'adressa ${ }^{76} \mathrm{~d}^{\prime}$ algú.

Jo sé de gent que prou m'acompanyaria de gust, que són a Bruselles, ${ }^{77}$ els Casabó ${ }^{78}$ que he donat classes a la senyora (Suqué, Carme), però no tinc l'adressa ${ }^{79}$ ni manera de demanar-ho.

Escric a l'hotel en espera de les seves noves ràpides, car justament ja comptava tornar-me'n, em feia angúnia haver d'ésser mantinguda en tot i bé caldrà recomençar el curs, a més.

Tinc un permís [de la] Junta de Relacions Culturals, que en tot cas podria estirar, però no crec poguer-me ${ }^{80}$ quedar gaire. Esperaré contesta per emprendre viatge.

M'ha obert móns, ${ }^{8 \mathrm{I}}$ portes, somnis, vides, astres, camins. Tot i que no hi hagué cap, en absolut, cap intenció meva de demanar-li res, he conegut, he reconegut la faç d'aquell sentiment preat, envilit a voltes, noble i alt, que és el signe del Crist.

\footnotetext{
72 Lapsus per perquè.

73 Lapsus per perquè.

74 Lapsus per Brussel-les.

75 Lapsus per de pressa.

76 Lapsus per adreça.

77 Lapsus per Brussel-les.

78 La família del polític Josep M. Casabò i Torras, diputat de la Lliga, que va fugir de Barcelona en començar la guerra civil.

79 Lapsus per adreça.

8o Lapsus per poder-me.

8I Lapsus per mons.
} 
Gràcies. Si conegués l'adressa ${ }^{82}$ dels Cambó, ${ }^{83}$ ja compto que els escriuria, vostè, de passada? A la senyora. Com més ràpidament, millor. Que del Congrés d'Ha84 neixi llum, camins de vida nova.

Els saluda amb el més gran respecte, P. Jaquetti.

[Al marge dret:] Ah! saludi el professor Charles, dongui- ${ }^{85}$ li la meva adreça, si el veu, i Mme G. Hans. ${ }^{86}$

Senyor Patxot, obro per afegir dues coses molt boniques. Tot i l'estat elèctric i deprimit que comporta la guerra, acabo de fer cantar una dona, que ha passat per la muntanya i ha vingut a veure la filla, que serveix ací. Aquesta dona té fill i gendre al front, malgrat tot ha cantat tres cançons. Ara se'n torna, pels camins que li són tan coneguts i familiars - Així, no tot és empobrit, quan a l'ànima encara queden cançons i delit per cantar-les.

L'altra nova, acabo de rebre, del mestre Pau Casals, uns mots molt cars sobre el meu llibre i l'anunci d'una música que s'està escrivint d'un dels meus poemes, de la qual, em diu, rebré una còpia. No és el primer músic que m’ho diu, em fa una alegria immensa, que m'és molt grat d'obrir-li, com un perfum.

Un poema que és datat del 6 de juliol I938

Al Sr. Rafel Patxot, devotament

Emprendria un llarg viatge

sense camí

I duria, d'equipatge, l'anima ${ }^{87}$ en mi.

Fóra jo delint com ara?

Sota quin cel?

Hi ha una estrella que m'empara

dintre el seu vel

Quines terres petjaria?

Quina fe hi viu?

Fóra jo, la nova via,

solc d'argent viu?

Me n'iré sota el guiatge

de llum i vent

Quant duraria el viatge?

Eternament.

P. Jaquetti

82 Lapsus per adreça.

83 El polític Francesc Cambó, ben relacionat amb Patxot.

84 No sé de quin congrés es tracta.

85 Lapsus per doni.

86 Lectura aproximada. No sé identificar aquestes persones.

87 Lapsus per l'ànima. 


\title{
5. Carta manuscrita, Prats de Molló, 7 d'octubre de 1938
}

\author{
$S^{r}$ Rafel Patxot
}

Prats [de Molló], 7 oct I938

Preuadíssim i respectat senyor!

Tot i el meu propòsit i necessitat de tornar a casa, sóc encara ací, amargada pel sofriment, car és a causa del passaport. Ara fa un mes, ja em preparava a marxar i va haver-hi viatges de Mme i del passaport a Perpinyà, en lletra certificada. Es deia, ací, que s'havia de tornar a visar, per entornar-se'n.

Però el meu es veu que va sofrir, de part de l'home que no té altra feina a fer, a Cerbère, un oblit que motivà el retorn, per part del Préfet [de] Perpinyà, del passap[ort] dient que en entrar a França no havia estat marcat. Com q. jo no me l'havia de timbrar i vaig estar-me davant el senyor del despatx $\tan [\mathrm{t}]$ com va caldre, fins que me'l varen tornar, no sabia què hi havia de mancament meu, història ben trista per a mi, ara! Ací vaig ésser requerida al poble, vaig parlar amb el Batlle i amb la Gendarmerie i trobaren que el passaport ja estava bé. El 2I vaig retenir un lloc i vaig marxar. Però a la frontera, d'altra opinió, no em deixaren passar falta de visats.

En un taxi vaig a Perpinyà, obtinc el del C[onsolat] Espanyol, torno a Prefecture; ${ }^{88}$ aleshores s'adonen que cal enviar-lo al C[onsolat] Belga, (el meu passaport és Belga, com els meus anteriors) car a Barcelona han posat, (el C[onsolat] Francès) que era de passage en Belgique, ${ }^{89}$ tot i els papers presentats com a enviada per folklore, ací.

Ara el té el cònsol de Cette, ${ }^{\circ}$ únic Belga de per ací, i l'han hagut d'enviar a Bèlgica, em diu per telefon, ${ }^{9 \mathrm{I}}$ fa sis dies. Ja en fa I5 que hi és, i jo puc ésser destituïda, entre tant, pel Ministeri, car el meu permís només és de la Generalitat. Vostè podria, així que rebi aquesta, interessar algú de Brussel-les perque ${ }^{92}$ vagi immediatament a donar fe de mi i ocupar-se que em retornin el passaport en condicions de tornar a casa? Sóc en un recó de muntanya, i sola, car aquesta senyora només m’ha limitat l'acció, tota la seva intervenció ha estat inútil i perjudicial pel temps que hem perdut. Em cal, igualment, allà baix, algú que parli al Ministeri del meu cas, que vaig sortir per la salut, per uns dies i amb permís de Relac[ions] Culturals, i que en voler tornar, el 2I, han començat aquests entorpiments; que si no sóc allà el I5, retiraran els diners, i la meva mare, que és qui els necessita per la casa i per a ella i la noia, s'haurà de morir en la penúria.

També tenim pluja. Molta. Jo vaig escrivint, devorant llibres i turmentant-me, ara, car en tants dies el pass[aport] ja podria volar.

Vaig deixar passar el seu sant. Prou hi pensava. Esperava el pass[aport] d'un moment a l'altre. Ara ja no espero sinó alguna desgràcia i pèrdua de la carrera que tant m'ha costat.

88 Lapsus per Préfecture.

89 És a dir, de pas cap a Bèlgica.

90 Lapsus per Sète, Seta en català.

9I Lapsus per telèfon.

92 Lapsus per perquè. 
Ajudi'm, escrigui, sense dir-m'ho, a qui li sembli que m'ho pot mirar amb interès i ho ha de saber dir al Ministeri [d']Inst[rucció] Púb[lica]! El director [de l']Institut Pi i Margall, on sóc, no havia cregut [necessari], d'acord amb mi i per pocs dies, que havia ell de demanar permís al Ministeri i ara haurà de declarar que manco.

No sé què em passa! I aquesta gent, tots aquests gendarmes i Madams ${ }^{93}$ tan inútils, tan poc renseignés, ${ }^{94} \mathrm{i}$ la sola feina que tenen!

Mai no he tingut un goig, a la vida, que no se'm giri i no em costi llàgrimes.

També li volia dir: què deu tenir Hermínia, ${ }^{95}$ contra meu, que no m'ha escrit ni un sol cop, ni contestat des de que va tenir la sort de marxar a una vida més reposada i com cal? Si en sap alguna cosa, li prego de dir-me-la.

El saluda amb la més gran deferència

P. Jaquetti

\section{Carta manuscrita, Barcelona, 27 d'octubre de 1938}

Mr R. Joubert

Barcelone, le 27 oct. 1938

Très cher Monsieur! Me voilà déjà chez moi. Je vous remercie inmensément ${ }^{96}$ tout ce que vous avez tenté pour expliquer mon retard. Tout est arrangé, rien de dérangé. Je vous ai écrit au même moment où je quittais la France, pour vous ramener tout à fait sur la reception ${ }^{97}$ de mon passeport.

J'ai trouvé maman toute seule, la bonne nous ayant quitté il y avait déjà bien des jours, sournoisement, à cinq heures du matin, pour s'employer dans l'industrie qui remplit nos actuelles activités, où, dit-elle, on peut gagner davantage.

J'ai trouvé toutes les lettres et nouvelles que maman avait reçu pendant mon absence. Bien, bien merci.

Encore, je dois vous prier mes remerciements les plus reconnaissants à Mr Carreras, ${ }^{8}{ }^{8}$ qui vient d'envoyer un cadeau qui est presque arrivé en parfaite intégrité.

J'ai un grand calme, amassé là, au fond de la rivière, sous le soleil brûlant, dans la plus parfaite solitude. J'ai écrit bien des chansons et j'ai aussi préparé 99 une poésie aux montagnes, très simple, avec très peu d'images.

Je fais de mon mieux pour adapter mon vivre, mes jambes, mes habitudes, aux circonstances.

Dans mon besoin de me transporter à l'Institut, ayant à parcourir très longue distance, l'autobus, malgré une queue d'une heure et plus se faisant tout à fait imprenable, je m'arrange à pied et avec un bout de tram, et je réussis assez bien à

93 En francès, seria mesdames.

94 És a dir, informats.

95 Es tracta d'Hermínia Grau, muller d'Agustí Duran i Sanpere. Sé, gràcies a l'amabilitat d'Eulàlia Duran i Grau, que Patxot també havia ajudat la seva mare durant la guerra i que més endavant Palmira Jaquetti anava sovint a casa seva, a Barcelona, o hi trucava.

96 Lapsus per immensément.

97 Lapsus per réception.

98 Manuel Carreras, gendre de Patxot, que l'ajudava en la distribució d'ajudes als seus coneguts que eren a l'exili o que havien quedat a Barcelona.

99 Lectura dubtosa. 
maîtriser mes pensées et mon sentiment, si vif, de la justice. J'ai demandé au Ministère l'aide d'un autocar pour ces deux genoux operés. ${ }^{\text {Ioo }}$ Dans l'attente, je vais exactement à mon travail. Je réussis, personne me demande commment.

Comme v[ous] pensez à tout! Maman et moi en sommes si touchées! Moi, je ne m'étonne pas. Je sais. Je vous ai connu, et le premier jour je me suis sentie confiante de la bonté et de la justice et de l'élégante noblesse de notre race. Il suffit d'un, quoiqu'on désire que ce soit tout le monde. J'ai reçu des nouvelles de Mr Chalers. ${ }^{\text {Ior }}$ Oui, les grandes réserves spirituelles sont dans les cours que l'on révère. Le découragement ne peut pas me pénétrer, dans une vie horriblement solitaire et délaissée. Je ne me sens plus seule, quand je pense aux souffrances des autres. J'envoie une de mes chansons pour le tout petit des enfants.

Bien à vous, P. Jaquetti.

\title{
7. Carta manuscrita, Barcelona, 26 de novembre de 1938
}

\author{
Mr Raphaël Joubert
}

Barcelone, le 26 nov. $1938 .^{\text {I02 }}$

\section{Très cher Monsieur!}

J'ai reçu un splendide cadeau, qui m'est parvenu en parfaite intégrité, et dont notre santé vous est infiniment reconnaissante.

Nous n'avons plus de bonne. Elle nous a quittées pour une industrie qui paye davantage. Que voulez-vous? C'est le moment, il faut en profiter. Mais nous avons déjà fait plusieurs expériences, toutes douloureuses, et nous avons décidé de nous passer de services nominaux et nous nous partageons le travail avec maman. Elle fait le déjeuner, je prépare le reste et finis le petit ménage, nous avons une fille pour la grosse besogne, qui mange chez nous, c'est encore une condition sine qua non des gens de qui vous attendez quelque service, je me réserve les soirs ou les petits matins, où je plonge joyeusement dans mon travail.

Bien souvent, une affreuse intersection! J'ai aussitôt mon sang figé, tout mon corps bouleversé. Puis, on entend tomber ces horribles machines à tuer. Plus tard, un calme qui vient au son des sirènes. Mais le bruit seul suffit pour m'effrayer de nouveau.

Cette année, la vie devient encore plus dure. Je dois aller à pied!, je me transporte en sève, par cette douce chute des feuilles d'or, au cœur de la nature passible..

Mes genoux savent s'accomoder ${ }^{103}$ à la besogne, si dure soit-elle. Comme ils sont sages! J'en suis tout à fait touchée. Ce qui est encore plus dur et que j'endure péniblement, ce n'est (tout à coup, à ce moment, le bruit soudain du canon et la chute des bombes. C'est horrible, quelle misère que cette vie!) pas le manque de tram, c`est l'obscurité. Notre quartier, notre maison, n'a d'électricité que la nuit, depuis Io heures jusqu'à 5 heures du matin. C'est justement le temps que je donne au sommeil... Donc, je dois tout faire à la lumière de ma bougie, mais en-

Ioo Lapsus per opérés.

Ior Deu ésser el mateix Mr. Charles al qual s'ha referit abans.

IO2 A sota hi ha la indicació, en català, que fou rebuda el 2I de gener de 1939.

IO3 Lapsus per accommoder. 
core, j'ai terreur, de cette douzaine de bougies que j'ai apportées de France. Comment ferai-je après? Car il me faut préparer mes leçons, aussi je dois écrire et il me faut préparer encore des conférences. Enfin, toute ma vie de l'esprit, toute cette activité, qui, faute de bougie, devrait tarir.

Je suis très économe de ma lumière. Le matin, j'étains au premier rayon de lumière, je passe même dans une salle de bain dans la plus parfaite obscurité, et je prends le petit déjeuner avant le lever du soleil, car il faut, il fallait, car on vient de les supprimer - que je profitte ${ }^{\mathrm{I0} 4} \mathrm{du}$ tram de $8 \mathrm{~h}$. moins le quart, même quand ma classe ne commence qu'à in heures moins le quart, car j'épargne la moitié de mon chemin. Mais, dans tous le cas, il me faut partir très tôt et me rendre à pied à l'Institut. Aussi, mon service commence, presque tous les jours, à 8 h. 1/2 .

Je me trouve encore sans enveloppes, et je cherche inutilement les plus vulgaires, légères, comme tout à fait mon enveloppe-ci, et je n'en trouve plus.

J'ai honte de vous dire tout ceci, je sais à qui je le dis, je sais comme vous devinez les besoins de vos élèves. (En vous écrivant, j'en arrivais à m'oublier, dans un moment de calme, de ce qui se passe au dehors, mais le tremblement des moteurs me rend dans la triste réalité. j'y replonge un moment[)].

Il me faut beaucoup écrire, m'oublier, dans le rêve et dans le monde du beau,

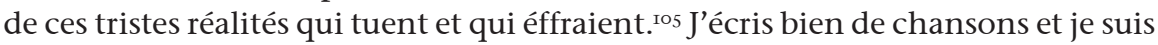
en train de continuer et de finir une poésie de montagne que j'avais commencée là-haut. Je réussis à en revivre le calme et la fraîcheur.

Je lis le Pickwick ${ }^{\mathrm{Io}}$ et pense bien souvent à vos mots, à vos propres malheurs. Je vous bénis, et je bénis, en vous, un chevalier de notre race, de notre langue, un chevalier qui n'a sur son bouclier que la justice et la vérité, et comme honneur le culte de ces $^{107}$ vertus. Cela suffit!

Je vous demande le prénom de vos petits-fils pour le mettre en tête de quelques unes de mes chansons.

Et je vous prie de m'écrire, de me faire le grand bienfait de votre parole, qui m'a fourni tant de paix et tant de bien, qui m'a accompagné jusque dans moi-même, où je me suis trouvée si parfaitement en sureté. ${ }^{108}$

Je vous prie des amitiés pour tous, sans oublier $\mathrm{M}^{\mathrm{r}}$ Charcas et Mme Gutheim.

Je vous enverrais bien volontiers du soleil, de ces magnifiques journées sans bornes, où le soleil de printemps se serait trompé. Je voudrais bien, de ma part, ajouter du soleil à des paysages mornes, mais je ne puis que vous dire, avec les meilleurs souhaits de mon âme! Au revoir!

Bien à vous,

Palmyre Jaquetti

IO4 Lapsus per profite.

I05 Lapsus per effraient.

Io6 La famosa novel-la de Charles Dickens, Pickwick (Documents pòstums del Club d'aquest nom), traduïda per Josep Carner, en tres volums (Badalona: Edicions Proa, I93I).

Io7 Lapsus per ses.

Io8 Lapsus per sûreté. 


\section{Carta manuscrita, Barcelona, 31 de desembre de $1938^{109}$}

$\mathrm{M}^{\mathrm{r}}$ le professeur Joubert

Barcelone, le 3i déc. I938

\section{Très cher Monsieur!}

J'ai bien reçu vos cartes et vos cadeaux, et ces deux fois-ci ils me sont parvenus au complet. Ici je m'arrête, je médite profondément, je n'ajoute rien. J'ai honte de vous dire seulement un mot de tout ce qui remplit mon âme. Merci, ce serait un petit mot ridicule. C'est en me taisant que je vous révère et vous remercie de mon mieux dans mon âme.

Je suis encore vaillante. Mon voyage et mes promenades m'ont apporté des forces dont je m'étonne moi-même, car il me faut, désormais, me rendre à pied à l'Institut. Je m'en tire assez bien et sans beaucoup de fatigue. Si madame Thérèse, cette excellent et très vieille personne était vivante et pouvait me voir, elle qui m'a vu et m'a entendu pousser des cris épouvantables quand on me tournait, comme une tante, sur mon lit! Il y a longtemps qu'elle est morte.

Pendant ces jours, j'écris bien des chansons. Il y a deux ans, c'étaient des chansons et des poèmes où je chantais le parfum, la joie de ces fêtes d'amour et de famille. Maintenant ce sont déjà plus précises, elles veulent s'ajouter en ruisseaux étincelants aux belles ch[ansons] de Noël qui émerveillent encore le monde.

Je vous prie les meilleurs mots à votre famille et aux enfants. Aussi, si vous voyez Mr Cachard, ${ }^{\text {Iо }}$ si vous lui écrivez, je vous prie de lui dire les bons sentiments de son élève.

Je ne veux pas vous parler de nos souffrances. Il tombe (au milieu du jour, du ciel pur et d'une beauté merveilleuse), il grêle des bombes, la nuit. On endure tant, et on apprend à se passer de bien de choses et surtout, à adapter la vie aux circonstances. Le mimétisme des petits animaux peut même s'appliquer au genre humain dans les plus dures circonstances. Ainsi, le chauffage peut se réduire à une bouillotte et la table à chère peut se réfugier dans le lit en petite planche. Quand on réussit à faire de la vie la chose la plus simple et quand nos besoins se trouvent réduits au minimum, voilà qu'on est encore heureuse au milieu des souffrances, sous le ciel qui s'épanouit et se donne toujours en nappes de lumière.

Je manque de beurre, absolument nécessaire à mes os, et de bougies. Mais je trouverai moyen de me tirer d'affaire. D'abord, il me reste encore un petit bout de bougie, car nous avons eu assez de lumière électrique pendant quelques jours. Puis, les journées seront plus claires, cela recommence. En été, j'avais organisé ma vie de sorte que je ne devais même pas allumer.

Je puise dans mon propre monde intérieur tous les éléments dont l'ai besoin pour peupler ma solitude. Maman est beaucoup mieux et très vaillante et courageuse, aussi. Elle vous envoie ses meilleurs amitiés.

Io9 A sota, hi ha la indicació, en català, que fou rebuda el 2I de gener de I939. Al començament de la carta hi ha enganxada una petita Note de la censure, impresa, que demana que, per a la resposta, s'utilitzi amb preferència «la carte postale», amb lletra ben clara i tan curta com sigui possible. «Les lettres trop longues pourraient subir des retards et même être arrêtées par la censure».

IIo No podem identificar aquest personatge, que Palmira qualifica d'antic mestre, potser, com altres vegades, per temes de censura. 
Et moi, je ne saurais pas me passer d'envoyer, pour les petits, une de mes chansons. J'ai été dans les deux Ecoles Normales, on me dit bien de belles choses de mes chansons, me ${ }^{I I I}$ je me sens seule et j'écris, j'écris toujours.

Cançó del ferrer

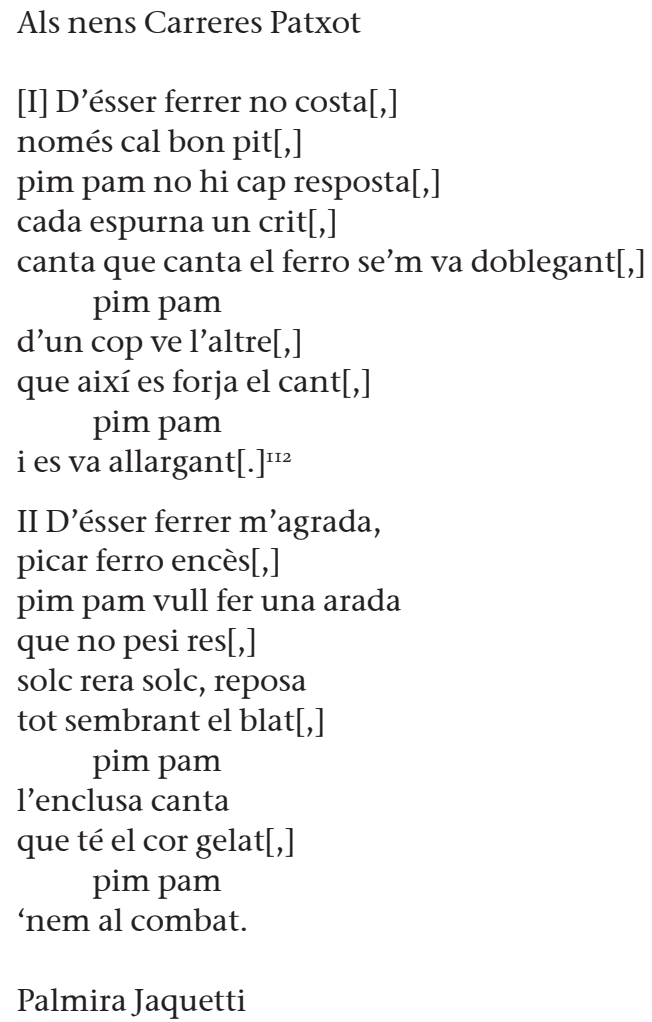

9. Carta manuscrita, Barcelona, 23 de gener de 1939 [enllestida el 26 de gener $]^{113}$

$\mathrm{M}^{\mathrm{r}}$ le Prof. Joubert

Barcelone, le 23 janvier I939

Très cher Monsieur! Je viens de recevoir vos cadeaux, presque intègres.

Les chemins étant si longs et si difficiles, je ne m'étonne pas.

Je ne saurais vous dire ma joie, ma gratitude!

Je me réfugie dans mes souvenirs, dans ma vie, dans l'amitié, dans la beauté de la nature, je crée, j'écris constamment, jusqu'ici j'ai encore tenue, hier, au-

III Deu haver de dir mais.

II2 Aquesta primera estrofa va acompanyada de la melodia corresponent.

II3 A sota hi ha la indicació, en català, que fou rebuda el 27 de febrer [de I939]. 
jourd'hui, tous les jours c'est le même travail, la même corvée, une souffrance qui ne fait que s'accroître.

Désormais, je me rends à pied au Lycée. Je rentre à pied, je vais toute seule, avec ma canne; c'est en tout, une heure et demie de marche. Mais c'est trop. Aussi, j'endure les escaliers toutes les fois qu'il y a bombardement, car on est obligé de faire descendre les enfants en bas. Hier je suis montée et descendue au sixième seize fois. Puis, la nuit. Ces nuits! Oh, que je pense à vous!

Je plonge dans ma propre vie intérieure, dans le rêve, dans la poésie qui se détache de tout. J'ai réussi, jusqu'à ce jour, à me tenir. Mais je me sente extrêmement fatiguée et lasse. Ma lettre est souvent interrompue. Les bombes, les canons. J'ai l'âme meurtrie.

Et ce soleil! Cette chaude lumière qui est vie, joie, beauté. Et la mort de tous côtés!

Ici, je ne pouvais plus écrire. Il s'est passé quelques jours depuis le commencement de ma lettre et le dernier événement. Aujourd'hui, le 26 janvier. L'armée de Franco vient d'entrer à Barcelone et voici qu'ils parlent par la radio. J'ai encore les sirènes, les constantes sirènes de ces jours derniers, dans le cœur, dans le sang. Ces coups de canon dont je ne distinguais que le bruit s'approchant, résonnent encore dans mon corps. Il y a encore quelques heures, j'ai pleuré chaudement dans ma fenêtre. La foule venait de tous côtés traînant des sacs de riz, des morues, des boîtes, des caisses, et pendant de longues heures tous les vivres emmagasinés ont été pris; en un moment les gens se sont munis de ce qui coutaitıı4 de longs jours de guerre et de souffrance. Ils se battaient, en chemin, se poursuivaient, pour se prendre encore leur proie. Des gens qui tombaient, des lentilles qui abreuvaient le sol, des femmes qui se basculaient et piétinaient pour les ramasser, des cris, des injures, des grossièretés, II5 des courses, des fuites avec une nouvelle boîte prise en chemin, voilà ce qui m'a ému profondément, tandis que je pensais à bien de choses.

Je suis tout à fait malade. Puis ces longues courses que mes genoux devraient endurer, cette soif de paix, de repos! Ah! Je vous écrirai au plus tôt. P. Jaquetti

II4 Lapsus per coûtait.

II5 Lapsus per grossièretés. 


\section{Referències bibliogràfiques}

Calbet, Josep M.; Jacint Corbella (I983): Diccionari biogràfic de metges catalans, III. Barcelona: Fundació Salvador Vives i Casajuana.

CARDona, Osvald (I964): «Record de Palmira Jaquetti». Serra d'Or núm. 2/3: 76.

DoMÈnECH, Salvador (I998): L'Institut-Escola de la Generalitat i el doctor Estalella. Barcelona: Publicacions de l'Abadia de Montserrat.

GONZÁLEZ-AGÀPITO, Josep; Salomó MARQUÈs (I996): La repressió del professorat a Catalunya sota el franquisme (I939-I943) segons les dades del Ministeri d'Educació Nacional. Barcelona: Institut d'Estudis Catalans.

MAssot, Josep (ed.) (I995): Obra del Cançoner Popular de Catalunya. Materials, V. Barcelona: Publicacions de l'Abadia de Montserrat.

- (2004a): Obra del Cançoner Popular de Catalunya. Materials, XIV. Barcelona: Publicacions de l'Abadia de Montserrat.

- (2004b): «L'Obra del Cançoner Popular de Catalunya, font de recerques». Dins Escriptors i erudits contemporanis. Quarta sèrie. Barcelona: Publicacions de l'Abadia de Montserrat, p. I69-I88.

- (20IO): Obra del Cançoner Popular de Catalunya. Materials, XX. Barcelona: Publicacions de l'Abadia de Montserrat.

- (20I4): Rafael Patxot i Jubert. El savi, el mecenes, el patriota. Barcelona: Publicacions de l'Abadia de Montserrat.

— (20I9): «Noves aportacions a l'Obra del Cançoner Popular de Catalunya». Dins A la Ciutat dels llibres. Tercera sèrie. Barcelona: Publicacions de l'Abadia de Montserrat, p. 6I-74.

— (2020a): «Baltasar Samper, de l'Obra del Cançoner a França i a Mèxic». Dins $A$ la Ciutat dels llibres. Quarta sèrie. Barcelona: Publicacions de l'Abadia de Montserrat, p. 69-II8.

- (en premsa): Les missions de l'Obra del Cançoner Popular de Catalunya. Barcelona: Publicacions de l'Abadia de Montserrat.

MATHEU, Roser (1972): Quatre dones catalanes. Barcelona: Fundació Salvador Vives Casajuana.

OrIOL, Carme; Emili SAMPER (eds.) (20I7): Història de la literatura popular catalana. Alacant/Palma/Tarragona: Edicions de la Universitat Rovira i Virgili/Publicacions de la Universitat d'Alacant/Edicions de la Universitat de les Illes Balears.

SERRAHIMA, Maurici (I98I): Memòries de la guerra i de l'exili, 2 vols. Barcelona: Edicions 62.

ToMÀs, Jordi (2008): El mestre Joan Tomàs i Parés: passió per la cançó popular. Barcelona: Publicacions de l'Abadia de Montserrat. 